\title{
Editorial
}

\section{Karl-Heinz Paqué*}

\section{Auf dem Weg in eine neue Welt?}

https://doi.org/10.1515/pwp-2018-0021

\section{Liebe Leserin, lieber Leser,}

vor 100 Jahren endete der Erste Weltkrieg. Wie kaum ein anderes historisches Ereignis veränderte er die Welt: Das liberale neunzehnte Jahrhundert, das politisch und wirtschaftlich noch ein Stück in das zwanzigste hineingeragt hatte, kam zu seinem endgültigen Abschluss. Darüber sind sich Zeithistoriker im Rückblick einig.

Die große Frage ist nun: Stehen wir heute wie damals vor oder schon mitten in einer Zeitenwende? Glücklicherweise gibt es keinen globalen Krieg, der dies nahelegen könnte. Aber es gibt erstaunlich breite und tiefe ökonomische Veränderungen, die doch eine Art „tektonische“ Verschiebung von internationalen Herausforderungen nahelegen könnten. Wenn dem aber so ist, dann könnte eine ganz neue Agenda der Wirtschaftspolitik entstehen.

Genau diese Agenda behandeln die meisten Beiträge in diesem Heft, explizit oder implizit, und zwar in ganz verschiedenen Dimensionen. Niels Geiger, Klaus Prettner und Johannes Schwarzer liefern in der Rubrik „Wissenschaft im Überblick“ einen Survey zu den Auswirkungen der digitalen Automatisierung auf Wachstum, Beschäftigung und Ungleichheit - vielleicht die fundamentalste Zukunftsfrage in unseren hochentwickelten Industrienationen. Ihre Antwort ist auf Grundlage der wissenschaftlichen Evidenz differenziert: Größere Chancen für mehr Prosperität und schnelleres Wachstum sind erkennbar, aber ebenso verschärfte Risiken einer weiteren Spaltung unserer Gesellschaften in Gewinner und Verlierer der Automatisierung.

In drei Beiträgen der Rubrik „Aus aktuellem Anlass“ geht es um unterschiedliche Aspekte der Globalisierung. Henning Klodt schreibt über die neue Welle des Protektionismus, angeschoben durch den amerikanischen Präsidenten Donald Trump mit seiner Politik des „America First“. Wolfram Richter befasst sich mit neuen Formen der Gewinnbesteuerung im Fall von international gehandelten, digitalisierten Dienstleistungen. Adalbert Winkler setzt sich mit den neuen geldpolitischen Strategien der

*Kontaktperson: Karl-Heinz Paqué, Otto-von-Guericke-Universität Magdeburg, E-Mail: paque@ovgu.de

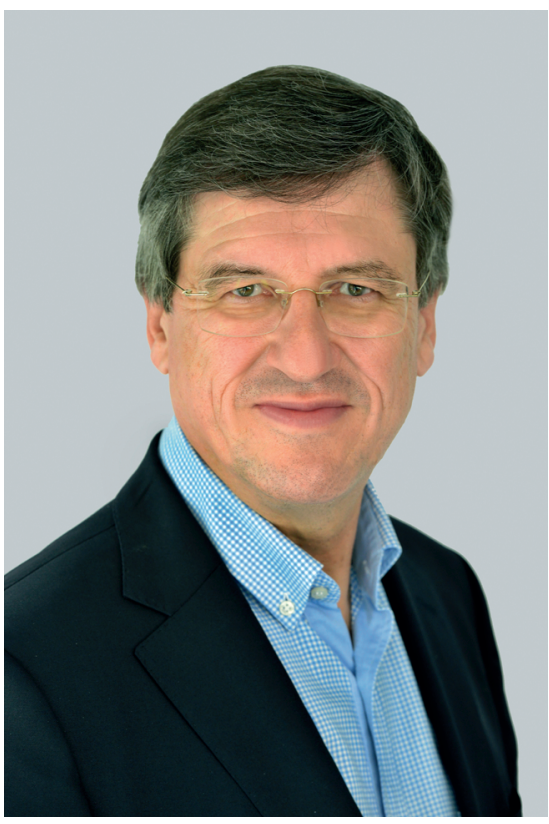

Zentralbanken in den zehn Jahren seit dem Beginn der Weltfinanzkrise 2008 und der scharfen Kritik auseinander, die diese Strategien auch in der deutschsprachigen Öffentlichkeit provoziert haben. Den drei Beiträgen ist gemeinsam, dass ihre Autoren - inspiriert von Ereignissen und Trends der vergangenen Jahre - ein innovatives Denken anmahnen, das harte veränderte Realitäten zur Kenntnis nimmt und daraus weitreichende wirtschaftspolitische Schlüsse zieht, anstatt in alten Bahnen zu verharren. Die Schlussfolgerungen sind dabei durchaus kontrovers, und das sollen sie auch sein, denn davon lebt die wissenschaftliche und politische Diskussion, heute mehr denn je.

Auch in der Rubrik „Das Gespräch“ geht es um neues Denken. Albrecht Ritschl, Wirtschaftshistoriker an der London School of Economics, sinniert im Interview mit Karen Horn und mir über die Frage, ob wir überhaupt aus der Geschichte lernen. Ein provokanter Satz von ihm dient als Überschrift: „Wir haben deutlich gelernt, dass wir nichts gelernt haben." Dies gilt für ihn vor allem mit Blick auf die großen makroökonomischen Krisen des 20. Jahrhunderts. Mit einer leichten Prise Selbstironie könnte die Lehre auch lauten: Ein wenig mehr Bescheidenheit stünde uns Volkswirten und Politikern nicht schlecht zu Gesicht. 
Schließlich enthält das Heft zwei Beiträge in der Rubrik „Aus der Forschung“. Giacomo Corneo liefert ein wohlfahrtstheoretisch fundiertes Plädoyer für die Einführung eines Staatsfonds, der eine soziale Dividende finanziert. Es ist ein Thema, das sich zunehmend aufdrängt: durch niedrige, zum Teil gar negative Realzinsen für die Staatspapiere von Nationen mit exzellenter Bonität wie
Deutschland, Österreich und die Schweiz. Und Thomas Neusius analysiert den Wettbewerb um Bestandskunden in der Privaten Krankenversicherung mit Blick auf die aktuelle wissenschaftliche und politische Diskussion zur Übertragbarkeit von Altersrückstellungen.

Karl-Heinz Paqué 